Cochrane Database of Systematic Reviews

\title{
Clonazepam for neuropathic pain and fibromyalgia in adults
} (Review)

Corrigan R, Derry S, Wiffen PJ, Moore RA

Corrigan R, Derry S, Wiffen PJ, Moore RA.

Clonazepam for neuropathic pain and fibromyalgia in adults.

Cochrane Database of Systematic Reviews 2012, Issue 5. Art. No.: CD009486.

DOI: 10.1002/14651858.CD009486.pub2.

www.cochranelibrary.com 
ABSTRACT 1

PLAIN LANGUAGE SUMMARY

BACKGROUND

OBJECTIVES

METHODS

RESULTS

DISCUSSION

AUTHORS' CONCLUSIONS

REFERENCES

CHARACTERISTICS OF STUDIES

APPENDICES

WHAT'S NEW

HISTORY

CONTRIBUTIONS OF AUTHORS

DECLARATIONS OF INTEREST

SOURCES OF SUPPORT

INDEX TERMS

\section{TABLE OF CONTENTS}


[Intervention Review]

\section{Clonazepam for neuropathic pain and fibromyalgia in adults}

Ruth Corrigan ${ }^{1}$, Sheena Derry², Philip J Wiffen ${ }^{3}$, R Andrew Moore 4

1Pain Research and Nuffield Department of Clinical Neurosciences (Nuffield Division of Anaesthetics), University of Oxford, Oxford, UK.

2Oxford, UK. ${ }^{3}$ Thame, UK. ${ }^{4}$ Plymouth, UK

Contact: Sheena Derry, Oxford, Oxfordshire, UK. sheena.derry@retired.ox.ac.uk.

Editorial group: Cochrane Pain, Palliative and Supportive Care Group.

Publication status and date: Stable (no update expected for reasons given in 'What's new'), published in Issue 5, 2019.

Citation: Corrigan R, Derry S, Wiffen PJ, Moore RA. Clonazepam for neuropathic pain and fibromyalgia in adults. Cochrane Database of Systematic Reviews 2012, Issue 5. Art. No.: CD009486. DOI: 10.1002/14651858.CD009486.pub2.

Copyright $@ 2019$ The Cochrane Collaboration. Published by John Wiley \& Sons, Ltd.

\section{A B S T R A C T}

\section{Background}

Antiepileptic drugs have been used in pain management since the 1960s; some have shown efficacy in treating different neuropathic pain conditions. Clonazepam, a benzodiazepine, is an established antiepileptic drug, but its place in the treatment of neuropathic pain is unclear.

\section{Objectives}

To assess the analgesic efficacy and adverse effects of the antiepileptic drug clonazepam in neuropathic pain and fibromyalgia.

\section{Search methods}

We searched the Cochrane Central Register of Controlled Trials (CENTRAL) (The Cochrane Library 2012, Issue 2). MEDLINE, and EMBASE to 28 February 2012, together with reference lists of retrieved papers and reviews, and ClinicalTrials.gov.

\section{Selection criteria}

We planned to include randomised, double-blind studies of eight weeks duration or longer, comparing clonazepam with placebo or another active treatment in chronic neuropathic pain or fibromyalgia.

\section{Data collection and analysis}

Two review authors would independently extract data for efficacy and adverse events, and examine issues of study quality.

\section{Main results}

We did not identify any studies that satisfied the inclusion criteria.

\section{Authors' conclusions}

This review uncovered no evidence of sufficient quality to support the use of clonazepam in chronic neuropathic pain or fibromyalgia.

\section{PLAIN LANGUAGE SUMMARY}

\section{Clonazepam for neuropathic pain and fibromyalgia in adults}

Nerves which have been damaged by injury or disease can continue to produce pain. This type of pain is called neuropathic pain. Some antiepileptic medications can help neuropathic pain. Clonazepam is an antiepileptic medication, and the aim of this review was to assess how effective clonazepam is for neuropathic pain and fibromyalgia. We identified no good quality studies of clonazepam used in this situation. Dependence and tolerance may occur with prolonged use, although it is less of a problem with clonazepam than many 
other drugs from the same class (benzodiazepines), and behavioural disinhibition has been reported in a few patients with psychiatric problems. Based on current evidence, clonazepam cannot be recommended for treating neuropathic pain. Other antiepileptic drugs such as pregabalin, gabapentin, and carbamazepine have been shown to be of value in neuropathic pain. 


\section{B A C K G R O U N D}

\section{Description of the condition}

Neuropathic pain, unlike nociceptive pain such as gout and other forms of arthritis, is caused by nerve damage, often accompanied by changes in the central nervous system (CNS). The new (2011) definition of neuropathic pain is "pain caused by a lesion or disease of the somatosensory system" (Jensen 2011). Fibromyalgia is a complex pain syndrome, defined as widespread pain for longer than three months with pain on palpation at 11 or more of 18 specified tender points (Wolfe 1990), and frequently associated with other symptoms such as poor sleep, fatigue, and depression. More recently, a definition of fibromyalgia has been proposed based on symptom severity and the presence of widespread pain (Wolfe 2010). The cause or causes of fibromyalgia are not well understood, but it has features in common with neuropathic pain, including changes in the CNS. Cognitive dysfunction is another recently recognised feature of fibromyalgia (Reyes del Paso 2012). Many people with these conditions are significantly disabled with moderate or severe pain for many years. Conventional analgesics are usually not effective, although opioids may be in some individuals. Others may derive some benefit from a topical lidocaine patch or topical capsaicin. Treatment is more usually by unconventional analgesics such as antidepressants or antiepileptics.

Data for the incidence of neuropathic pain are difficult to obtain. However, a systematic review of prevalence and incidence in the Oxford Region of the UK indicates prevalence rates per 100,000 of 34 for postherpetic neuralgia, 400 for diabetic neuropathy and trigeminal neuropathy, and 2000 for fibromyalgia (McQuay 2007). Different estimates in the UK indicate incidences per 100,000 person-years observation of 40 (95\% confidence interval (CI) 39 to 41) for post-herpetic neuralgia, 27 (26 to 27 ) for trigeminal neuralgia, 1 ( 1 to 2 ) for phantom limb pain, and 15 (15 to 16) for painful diabetic neuropathy, with rates decreasing in recent years for phantom limb pain and post-herpetic neuralgia and increasing for painful diabetic neuropathy (Hall 2006). The prevalence of neuropathic pain in Austria was reported as being 3.3\% (Gustorff 2008). The largest recent study in France found a prevalence of $7 \%$ (Bouhassira 2008).

Neuropathic pain and fibromyalgia are difficult to treat effectively, with only a minority of individuals experiencing a clinically relevant benefit from any one intervention. A multidisciplinary approach is now advocated, with physical or cognitive, or both, therapies being combined with pharmacological interventions.

\section{Description of the intervention}

Clonazepam is a benzodiazepine, based upon the unusual sevenmembered ring and aromatic ring structure that is common to all compounds in this group. Historically, the first benzodiazepine, chlordiazepoxide, was discovered accidentally in the late 1950s as a result of an unplanned reaction at the Roche laboratory, and after routine screening its unexpected pharmacological activity was recognised. Benzodiazepines bind specifically to $G_{A B A}$ (gammaaminobutyric acid) receptors at a binding site different to that occupied by GABA, the main inhibitory neurotransmitter in the CNS. Allosteric binding to this ligand-gated ion channel increases its affinity for GABA and therefore facilitates the opening of GABAactivated chloride channels. This enhanced inhibitory response to
GABA is thought to be the mechanism behind the main effects of benzodiazepines, namely reduced anxiety, sedation, relaxation of muscle tone, and an anticonvulsant effect.

Clonazepam (trade names: Rivotril and Klonopin) is unusual because it has a very long half-life (approximately 35 hours) and marked anticonvulsant effects with less marked sedation compared to other benzodiazepines. However, as with all benzodiazepines, the generation of tolerance and dependence is of concern. It has also been associated with behavioural disinhibition in patients with psychiatric conditions (e.g. Binder 1987), although other studies have not demonstrated this (e.g. Rothschild 2000). The British National Formulary lists aggression as one of the paradoxical adverse effects (BNF 2011)

Clonazepam is indicated for the treatment of myoclonic, atypical absence, atonic and tonic epileptic seizures, as well as status epilepticus and can be administered orally (4 to $8 \mathrm{mg}$ daily maintenance dose) or intravenously ( $1 \mathrm{mg} / \mathrm{ml}$ ampoules available). Intravenous administration is outside the scope of this review because it is not relevant to chronic treatment. We are unaware of any license for use in neuropathic pain or fibromyalgia.

\section{How the intervention might work}

At the molecular level the pathophysiology of both neuropathic pain and fibromyalgia is unclear but both may involve changes to several neurotransmitter systems including those involving substance $\mathrm{P}$, NMDA (N-Methyl-D-aspartic acid), GABA, and opioids. Clonazepam may have a beneficial effect in the treatment of neuropathic pain and fibromyalgia by antagonising hyperexcitability of neurotransmission through the enhancement of inhibitory GABAergic signalling pathways. However, there is no consensus as to both how and even whether clonazepam exerts analgesic effects in these conditions. An earlier Cochrane review, 'Anticonvulsants in acute and chronic pain' (Wiffen 2010) (withdrawn because it is out of date and has been superseded by other reviews of individual drugs, such as this one) found one study in temporomandibular joint dysfunction.

\section{Why it is important to do this review}

Some antiepileptic drugs have shown some efficacy in neuropathic pain and fibromyalgia (e.g. gabapentin (Moore 2011), pregabalin (Moore 2009a), and carbamazepine (Wiffen 2011a)), while others do not (e.g. lamotrigine Wiffen 2011b), and for others there are no data (e.g. phenytoin (Birse 2012)). It is important to establish whether clonazepam has a place amongst the available treatment options for these conditions.

There have been several recent changes in how efficacy of conventional and unconventional treatments is assessed in chronic painful conditions. The outcomes are now better defined, particularly with the addition of new criteria on what constitutes moderate or substantial benefit (Dworkin 2008); older trials may only report participants with "any improvement". Newer trials tend to be larger, avoiding problems from the random play of chance. Newer trials also tend to be longer, up to 12 weeks, and longer trials provide a more rigorous and valid assessment of efficacy in chronic conditions. New standards have evolved for assessing efficacy in neuropathic pain, and we are now applying stricter criteria for inclusion of trials and assessment of outcomes, and are more aware of problems that may affect our overall assessment (Moore 2010). 
To summarise some of the recent insights that make a new review necessary, over and above including more trials, are as follows:

1. Pain results tend to have a U-shaped distribution rather than a bell-shaped distribution (see Moore 2005 for acute pain). This is true in acute pain and arthritis (Moore 2009b) as well as in fibromyalgia; in all cases average results usually describe the experience of almost no one in the actual trial. Data expressed as averages are potentially misleading, unless it can be proven that they are suitable.

2. As a consequence, we have to depend on dichotomous results (the individual either has or does not have the outcome) usually from pain changes or patient global assessments. The IMMPACT group has helped with their definitions of minimal, moderate, and substantial improvement (Dworkin 2008). In arthritis, trials shorter than 12 weeks, and especially those shorter than eight weeks, overestimate the effect of treatment (Moore 2009b); the effect is particularly strong for less effective analgesics, and this may also be relevant in neuropathic-type pain.

3. The proportion with at least moderate benefit can be small, even with an effective medicine, falling from $60 \%$ with an effective medicine in arthritis, to $30 \%$ in fibromyalgia (Moore 2009b; Straube 2008; Sultan 2008). A Cochrane review of pregabalin in neuropathic pain and fibromyalgia demonstrated different response rates for different types of chronic pain (higher in diabetic neuropathy and postherpetic neuralgia and lower in central pain and fibromyalgia) (Moore 2009c). This indicates that different neuropathic pain conditions should be treated separately from one another, and that pooling should not be done unless there are good grounds for doing so.

4. Finally, presently unpublished individual patient analyses indicate that patients who get good pain relief (moderate or better) have major benefits in many other outcomes, affecting quality of life in a significant way.

This Cochrane review will therefore assess evidence in ways that make both statistical and clinical sense. Trials included and analysed will need to meet a minimum of reporting quality (blinding, randomisation), validity (duration, dose and timing, diagnosis, outcomes, etc), and size (ideally a minimum of 500+ participants in a comparison in which numbers needed to treat to benefit (NNTs) are four or above (Moore 1998)). This does set high standards, and marks a departure from how reviews have been conducted previously.

\section{OB JECTIVES}

1. To assess the analgesic efficacy of clonazepam for chronic neuropathic pain and fibromyalgia.

2. To assess the adverse events associated with the clinical use of clonazepam for chronic neuropathic pain and fibromyalgia.

\section{METHODS}

\section{Criteria for considering studies for this review}

\section{Types of studies}

We planned to include studies in this review if they were randomised controlled trials (RCTs) with double-blind assessment of outcomes reported after eight weeks of treatment or longer. Full journal publication was required, with the exception of extended abstracts of otherwise unpublished clinical trials. Short abstracts (usually meeting reports) were not included. We excluded studies that were non-randomised, studies of experimental pain, case reports, and clinical observations.

\section{Types of participants}

Adult participants aged 18 years and above were eligible for inclusion. Participants could have one or more of a wide range of chronic neuropathic pain conditions including:

- painful diabetic neuropathy;

- post-herpetic neuralgia;

- trigeminal neuralgia;

- phantom limb pain;

- postoperative or traumatic neuropathic pain;

- complex regional pain syndrome;

- cancer-related neuropathy;

- Guillain Barré;

- HIV neuropathy;

- spinal cord injury; or

- fibromyalgia.

Studies of participants with more than one type of neuropathic pain would also be included. We planned to analyse results according to the primary condition.

\section{Types of interventions}

Clonazepam in any dose, administered orally or intravenously for the relief of neuropathic pain or fibromyalgia, and compared to placebo, no intervention or any other active comparator. Studies using clonazepam to treat pain resulting from the use of other drugs were not included.

\section{Types of outcome measures}

We anticipated that a variety of outcome measures would be used in the studies. The majority of studies were expected to use standard subjective scales for pain intensity or pain relief, or both. Particular attention would be paid to IMMPACT definitions for moderate and substantial benefit in chronic pain studies (Dworkin 2008). These are defined as at least 30\% pain relief over baseline (moderate), at least 50\% pain relief over baseline (substantial), much or very much improved on Patient Global Impression of Change (PGIC) (moderate), and very much improved on PGIC (substantial). These outcomes are different from those set out in an earlier review of antidepressants for neuropathic pain (Saarto 2007), concentrating on dichotomous outcomes where pain responses are not normally distributed.

\section{Primary outcomes}

1. Patient-reported pain relief of $30 \%$ or greater.

2. Patient-reported pain relief of $50 \%$ or greater.

3. Patient-reported global impression of clinical change (PGIC) much or very much improved.

4. Patient-reported global impression of clinical change (PGIC) very much improved.

\section{Secondary outcomes}

1. Any pain-related outcome indicating some improvement.

2. Withdrawals due to lack of efficacy. 
3. Participants experiencing any adverse event.

4. Participants experiencing any serious adverse event.

5. Withdrawals due to adverse events.

6. Specific adverse events, particularly somnolence and dizziness.

\section{Search methods for identification of studies}

\section{Electronic searches}

We searched the following databases:

- the Cochrane Register of Controlled Trials (CENTRAL) (The Cochrane Library 2012, Issue 2);

- MEDLINE (via Ovid) (to 28 February 2012);

- EMBASE (via Ovid) (to 28 February 2012).

See Appendix 1 for the MEDLINE search strategy, Appendix 2 for the EMBASE search strategy, and Appendix 3 for the CENTRAL search strategy.

There was no language restriction.

\section{Searching other resources}

We searched the reference lists of retrieved articles and reviews, and ClinicalTrials.gov, for any relevant studies.

\section{Data collection and analysis}

\section{Selection of studies}

We determined eligibility by reading the abstract of each study identified by the search. We eliminated studies that clearly did not satisfy the inclusion criteria, and obtained full copies of the remaining studies. Two review authors read these studies independently and reached agreement on inclusion by discussion. The studies were not anonymised in any way before assessment.

\section{Data extraction and management}

We planned that two review authors would independently extract data using a standard form, and agree results before entry into RevMan 5 (RevMan 2011) or any other analysis method. Data extracted would include information about the pain condition and number of participants treated, drug and dosing regimen, study design (placebo or active control), study duration and follow-up, analgesic outcome measures and results, withdrawals and adverse events (participants experiencing any adverse event, or any serious adverse event).

\section{Assessment of risk of bias in included studies}

We planned to complete a 'Risk of bias' table to report on sequence generation, allocation concealment, blinding, and other risks such as size and imputation method for missing data.

\section{Measures of treatment effect}

We planned to calculate numbers needed to treat to benefit (NNTs) as the reciprocal of the absolute risk reduction (McQuay 1998). For unwanted effects, the NNT becomes the number needed to treat to harm (NNH), and is calculated in the same manner. Dichotomous data would be used to calculate risk ratio (RR) with $95 \%$ confidence intervals $(\mathrm{Cl})$ using a fixed-effect model unless significant statistical heterogeneity was found (see below). We did not plan to use continuous data because it is inappropriate where there is an underlying skewed distribution.

\section{Unit of analysis issues}

We would accept randomisation to individual participants only. The control treatment arm would be split between active treatment arms in a single study if the active treatment arms were not combined for analysis.

\section{Dealing with missing data}

We planned to use intention-to-treat (ITT) analysis. The ITT population would consist of participants who were randomised, took the assigned study medication, and provided at least one postbaseline assessment. Missing participants would be assigned zero improvement.

\section{Assessment of heterogeneity}

Clinical heterogeneity would be dealt with by combining studies that examine similar conditions. Statistical heterogeneity would be assessed visually (L'Abbé 1987) and with the use of the $\mathrm{I}^{2}$ statistic. If $I^{2}$ was greater than $50 \%$, reasons would be sought.

\section{Assessment of reporting biases}

The aim of this review was to use dichotomous data of known utility (Moore 2009b). The review would not depend on what authors of the original studies chose to report or not, though clearly there would be difficulties with studies failing to report any dichotomous results. Continuous data, which probably poorly reflect efficacy and utility, would be extracted and used only if useful for illustrative purposes.

We undertook no formal assessment of publication bias.

\section{Data synthesis}

We planned to use a fixed-effect model for meta-analysis. A random-effects model would be used if there was significant heterogeneity and it was considered appropriate to combine studies.

\section{Subgroup analysis and investigation of heterogeneity}

Subgroup analysis was to be undertaken for:

- dose of clonazepam;

- different painful conditions.

\section{Sensitivity analysis}

No sensitivity analyses were planned because the evidence base is known to be too small to allow reliable analysis. We would not pool results from neuropathic pain of different origins.

\section{RES U LTS}

\section{Description of studies}

\section{Results of the search}

The search identified three studies which we considered for inclusion. 


\section{Included studies}

None of the studies identified by the search strategy met the inclusion criteria set out in this review.

\section{Excluded studies}

We considered but excluded three studies. All studies were excluded as the duration of treatment was less than the eight weeks stipulated in the inclusion criteria. Furthermore we considered the pain syndromes investigated by these studies (temporomandibular joint dysfunction (Harkins 1991), burning mouth syndrome (Gremeau-Richard 2004), and jaw pain upon wakening (Herman 2002)) beyond the scope of this review. Finally, we also considered the topical application of clonazepam investigated by GremeauRichard 2004 to breach the inclusion criteria.

\section{Risk of bias in included studies}

There were no included studies to assess.

\section{Effects of interventions}

There were no included studies to assess.

\section{DISCUSSION}

\section{Summary of main results}

The literature search did not reveal any studies that met the inclusion criteria laid out in the protocol for this review. The inclusion criteria used here are based on modern standards for assessing the efficacy of pharmacological agents in neuropathic pain and the lack of studies fit for inclusion reflects the lack of recent interest in the systemic use of clonazepam in this context.

One paper (Gremeau-Richard 2004) assessed the use of topical clonazepam for the treatment of burning mouth syndrome (stomatodynia). This paper failed to meet the inclusion criteria for several reasons. Firstly both stomatodynia and topical application of clonazepam (as opposed to oral or intravenous administration of systemic clonazepam) are considered outside the scope of this review, and secondly the intervention period was just 14 days which is much shorter than the eight-week period stipulated by the inclusion criteria of this review. Of interest, however, this study found that patients who sucked a lozenge containing $1 \mathrm{mg}$ of clonazepam for three minutes three times per day for 14 days experienced significantly less pain than those given placebo when assessed five minutes after finishing the lozenge, as measured using a 14-point numerical scale. At least $50 \%$ pain relief was experienced by $11 / 24$ participants with clonazepam and $3 / 24$ with placebo, using an ITT) analysis. Three participants left the study due to side effects (sleepiness) or perceived lack of effectiveness.

Two further studies (Harkins 1991; Herman 2002) addressed the use of clonazepam for the treatment of two further pain conditions considered outside the scope of this review.

The first, a pilot study (Harkins 1991), investigated the effect of clonazepam on pain caused by temporomandibular joint dysfunction. Oral clonazepam was administered daily for 60 days (at a maximum dose of $1 \mathrm{mg} /$ day). Pain was assessed at baseline, day 30 , and day 60 using a visual analogue scale (VAS) to report both pain felt upon palpitation of specific sites by the examiner and perceived global pain levels of the head and neck. High drop-out rates in both the placebo and clonazepam groups (due to a perceived lack of improvement, or a perceived significant improvement, respectively) limited analysis in this study to just 30 days. However, at 30 days of clonazepam treatment both measures of pain were significantly reduced compared to placebo (approximately $40 \%$ to $50 \%$ reduction in reported pain after clonazepam treatment versus approximately $0 \%$ to $10 \%$ reduction in the placebo group).

The second (Herman 2002, 41 participants) compared the effectiveness of clonazepam and cyclobenzaprine to placebo in the treatment of jaw pain upon wakening. After three weeks of $0.5 \mathrm{mg}$ clonazepam neither the patients' reported pain upon wakening, assessed using a VAS, nor sleep quality, measured using the Pittsburgh Sleep Quality Index differed significantly from placebo.

As well as studying pain conditions outside the scope of this review, the intervention periods of the studies reported in both of these papers are also too short to meet the inclusion criteria of this review, and the numbers of participants treated were too small to permit any conclusions about efficacy.

Although these three studies were excluded here, Harkins 1991 and Gremeau-Richard 2004 have been included in previous reviews which discuss the role of clonazepam in the pharmacological management of neuropathic pain.

\section{Overall completeness and applicability of evidence}

We carried out an extensive literature search. It is unlikely that we have missed substantial amounts of relevant data.

\section{Agreements and disagreements with other studies or reviews}

Martin 2011 reviewed RCTs) of anticonvulsant drugs in the management of orofacial pain (including neuropathic pain). This review includes Gremeau-Richard 2004 which it declares to be of "high quality", yet the inclusion of only eight studies (of which only six were randomised controlled trials) analysing pain relief in five conditions limits the authors to conclude that there is insufficient evidence regarding the efficacy of anticonvulsants in orofacial pain disorders, with the exception of carbamazepine for the treatment of trigeminal neuralgia. Similarly, Gremeau-Richard 2004 is included in Patton 2007, which concludes that topical clonazepam and oral capsaicin are the only treatments for burning mouth syndrome that have robust placebo-controlled RCT evidence supporting their usage, with the caveat that in each case it is just one trial, and contrary to the many other treatments used in clinical practice.

McQuay 1995 reviewed RCTs of anticonvulsant drugs in the management of acute, chronic, or cancer pain. The review was not, however, limited to neuropathic pain and includes a study of clonazepam in migraine prophylaxis. Despite including Harkins 1991 the review concludes that more studies are required in order to provide persuasive high-quality evidence.

Tremont-Lukats 2000 described five studies of the use of clonazepam in the treatment of chronic neuropathic pain conditions dating back to 1975 , all of which demonstrated good improvements in the pain response. However, none of the studies included in this paper are RCTs. 
Not all recent systematic reviews of RCTs for the use of anticonvulsants to treat neuropathic pain include the studies relating to clonazepam. For example, the three reviews Finnerup 2010, Chou 2007 and Jensen 2009 review the comparative efficacy of drugs and different drug classes in the treatment of neuropathic pain but do not include any references to clonazepam.

Dworkin 2008 reviews current guidelines for treatment of neuropathic pain and discusses how recent studies should influence future guidelines. The authors make no reference to clonazepam or other anticonvulsants but raise the point that inadequate power of studies testing pharmacological agents against placebo in neuropathic pain renders them unhelpful in extrapolating their true efficacy. They conclude, much like this review, that to inform future treatment guidelines, high-quality RCTs must be conducted that directly compare medications for neuropathic pain with each other and placebo, providing a superior evidence base than currently exists.

Finally, clonazepam does not feature on the list of pharmacological treatments considered for the clinical guideline on neuropathic pain (NICE 2010). The American Association of Neurology guidelines for the treatment of painful diabetic neuropathy make no mention of the use of clonazepam in this context (AAN 2011).

\section{AUTHORS' CONCLUSIONS}

\section{Implications for practice}

This review has uncovered no evidence of sufficient quality to support a rationale for the use of clonazepam in chronic neuropathic pain and fibromyalgia, and the possibility of adverse effects is likely to curtail any potential use in these conditions. Other antiepileptic drugs such as pregabalin, gabapentin, and carbamazepine have been shown to be of value in neuropathic pain, and should be used in preference.

\section{Implications for research}

If clonazepam is to be considered for use in this context, highquality, randomised, double-blinded, placebo-controlled trials need to be carried out to build a base of evidence supporting its use or confirming it to be ineffective. Clonazepam is an old drug and this seems unlikely to occur due to the cost of such studies and the lack of financial incentive behind them, in this case because clonazepam is out of patent and there would be little or no profit to justify the large trial costs. 


\section{R E F E R E N C E S}

\section{References to studies excluded from this review}

\section{Gremeau-Richard 2004 \{published data only\}}

Gremeau-Richard C, Woda A, Navez ML, Attal N, Bouhassira D, Gagnieu MC, et al. Topical clonazepam in stomatodynia: a randomised placebo-controlled study. Pain 2004;108:51-7.

\section{Harkins 1991 \{published data only\}}

Harkins S, Linford J, Cohen J, Kramer T, Cueva L. Administration of clonazepam in the treatment of TMD and associated myofascial pain: a double blind pilot study. Journal of Craniomandibular Disorders: Facial and Oral Pain 1991;5:179-86.

\section{Herman 2002 \{published data only\}}

Herman CR, Schiffman EL, Look JO, Rindal DB. The effectiveness of adding pharmacologic treatment with clonazepam or cyclobenzaprine to patient education and self-care for the treatment of jaw pain upon awakening: a randomized clinical trial. Journal of Orofacial Pain 2002;16:64-70.

\section{Additional references}

\section{AAN 2011}

American Academy of Neurology. Treatment of painful diabetic neuropathy. www.aan.com/globals/axon/assets/8400.pdf (accessed 10 November 2011).

\section{Binder 1987}

Binder RL. Three case reports of behavioral disinhibition with clonazepam. General Hospital Psychiatry 1987;9(2):151-3.

\section{Birse 2012}

Birse F, Derry S, Moore RA. Phenytoin for neuropathic pain and fibromyalgia in adults. Cochrane Database of Systematic Reviews 2012, Issue 5.

\section{BNF 2011}

Joint Formulary Committee. Clonazepam. British National Formulary (online ed) : http://bnf.org/bnf/bnf/current/3577.htm (accessed 9 November 2011). Vol. 62, London: BMJ Group and Pharmaceutical Press, September 2011:Section 4.8.1.

\section{Bouhassira 2008}

Bouhassira D, Lantéri-Minet M, Attal N, Laurent B, Touboul C. Prevalence of chronic pain with neuropathic characteristics in the general population. Pain 2008;236(3):380-7. [DOI: 10.1016/ j.pain.2007.08.013]

\section{Chou 2007}

Chou R, Norris SL, Carson S, Chan BKS. Drug class review on drugs for neuropathic pain: final report. Drug Class Reviews. Portland: Oregon Health and Science University, 2007.

\section{Dworkin 2008}

Dworkin RH, Turk DC, Wyrwich KW, Beaton D, Cleeland CS, Farrar JT, et al. Interpreting the clinical importance of treatment outcomes in chronic pain clinical trials: IMMPACT recommendations. Journal of Pain 2008;9(2):105-21. [DOI: 10.1016/j.jpain.2007.09.005]

\section{Finnerup 2010}

Finnerup NB, Sindrup SH, Jensen TS. The evidence for pharmacological treatment of neuropathic pain. Pain 2010;150:573-81. [DOI: 10.1016/j.pain.2010.06.019]

\section{Gustorff 2008}

Gustorff B, Dorner T, Likar R, Grisold W, Lawrence K, Schwarz F, et al. Prevalence of self-reported neuropathic pain and impact on quality of life: a prospective representative survey. Acta Anaesthesiologica Scandinavica 2008;52(1):132-6.

\section{Hall 2006}

Hall GC, Carroll D, Parry D, McQuay HJ. Epidemiology and treatment of neuropathic pain: the UK primary care perspective. Pain 2006;122(1-2):156-62. [DOI: 10.1016/ j.pain.2006.01.030]

\section{Jensen 2009}

Jensen TS, Madsen CS, Finnerup NB. Pharmacology and treatment of neuropathic pains. Current Opinion in Neurology 2009;22:467-74. [DOI: 10.1097/WCO.0b013e3283311e13]

\section{Jensen 2011}

Jensen TS, Baron R, Haanpää M, Kalso E, Loeser JD, Rice AS, et al. A new definition of neuropathic pain. Pain 2011;152(10):2204-5. [DOI: 10.1016/j.pain.2011.06.017]

\section{L'Abbé 1987}

L'Abbé KA, Detsky AS, O'Rourke K. Meta-analysis in clinical research. Annals of Internal Medicine 1987;107:224-33.

\section{Martin 2011}

Martin WJJM, Forouzanfar T. The efficacy of anticonvulsants on orofacial pain: a systematic review. Oral Surgery, Oral Medicine, Oral Pathology, Oral Radiology and Endodontics 2011;111:627-33. [DOI: 10.1016/j.tripleo.2011.01.033]

\section{McQuay 1995}

McQuay H, Carroll D, Jada AR, Wiffen P, Moore A. Anticonvulsant drugs for management of pain: a systematic review. $B M J$ 1995;311:1047-52.

\section{McQuay 1998}

McQuay H, Moore R. An evidence-based resource for pain relief. Oxford: Oxford University Press, 1998. [ISBN: 0-19-263048-2]

\section{McQuay 2007}

McQuay HJ, Smith LA, Moore RA. Chronic pain. In: Stevens A, Raferty J, Mant J, Simpson S editor(s). Health Care Needs Assessment. Oxford: Radcliffe Publishing Ltd, 2007:519-600. [ISBN: 978-1-84619-063-6]

\section{Moore 1998}

Moore RA, Gavaghan D, Tramèr MR, Collins SL, McQuay HJ. Size is everything - large amounts of information are needed to overcome random effects in estimating direction and 
magnitude of treatment effects. Pain 1998;78(3):209-16. [DOI: 10.1016/S0304-3959(98)00140-7]

\section{Moore 2005}

Moore RA, Edwards JE, McQuay HJ. Acute pain: individual patient meta-analysis shows the impact of different ways of analysing and presenting results. Pain 2005;116(3):322-31. [DOI: 10.1016/j.pain.2005.05.001]

\section{Moore 2009a}

Moore RA, Straube S, Wiffen PJ, Derry S, McQuay HJ. Pregabalin for acute and chronic pain in adults. Cochrane Database of Systematic Reviews 2009, Issue 3. [DOI: 10.1002/14651858.CD007076.pub2]

\section{Moore 2009b}

Moore RA, Moore OA, Derry S, Peloso PM, Gammaitoni AR, Wang $\mathrm{H}$. Responder analysis for pain relief and numbers needed to treat in a meta-analysis of etoricoxib osteoarthritis trials: bridging a gap between clinical trials and clinical practice. Annals of the Rheumatic Diseases 2009;69(2):374-9. [DOI: 10.1136/ard.2009.107805]

\section{Moore 2009c}

Moore RA, Straube S, Wiffen PJ, Derry S, McQuay HJ. Pregabalin for acute and chronic pain in adults. Cochrane Database of Systematic Reviews 2009, Issue 3. [DOI: 10.1002/14651858.CD007076]

\section{Moore 2010}

Moore RA, Eccleston C, Derry S, Wiffen P, Bell RF, Straube S, et al. ACTINPAIN Writing Group of the IASP Special Interest Group on Systematic Reviews in Pain Relief, Cochrane Pain, Palliative and Supportive Care Systematic Review Group Editors. "Evidence" in chronic pain--establishing best practice in the reporting of systematic reviews. Pain 2010;150(3):386-9. [DOI: 10.1016/ j.pain.2010.05.011]

\section{Moore 2011}

Moore RA, Wiffen PJ, Derry S, McQuay HJ. Gabapentin for chronic neuropathic pain and fibromyalgia in adults. Cochrane Database of Systematic Reviews 2011, Issue 3. [DOI: 10.1002/14651858.CD007938.pub2]

\section{NICE 2010}

National Institute for Health and Clinical Excellence. Neuropathic pain: the pharmacological management of neuropathic pain in adults in non-specialist settings. http:// www.nice.org.uk/nicemedia/live/12948/47949/47949.pdf 2010.

\section{Patton 2007}

Patton LL, Siegel MA, Benoliel R, De Laat A. Management of burning mouth syndrome: systematic review and management recommendations. Oral Surgery, Oral Medicine, Oral Pathology, Oral Radiology and Endodontics 2007;103 Suppl(S39):e1-13. [DOI: 10.1016/j.tripleo.2006.11.009]

\section{RevMan 2011 [Computer program]}

The Nordic Cochrane Centre, The Cochrane Collaboration. Review Manager (RevMan). Version 5.1. Copenhagen: The Nordic Cochrane Centre, The Cochrane Collaboration, 2011.

\section{Reyes del Paso 2012}

Reyes Del Paso GA, Pulgar A, Duschek S, Garrido S. Cognitive impairment in fibromyalgia syndrome: the impact of cardiovascular regulation, pain, emotional disorders and medication. European Journal of Pain 2012;16(3):421-9. [DOI: 10.1002/j.1532-2149.2011.00032.x]

\section{Rothschild 2000}

Rothschild AJ, Shindul-Rothschild, Viguera A, Murray M, Brewster S. Comparison of the frequency of behavioral disinhibition on alprazolam, clonazepam, or no benzodiazepine in hospitalized psychiatric patients. Journal of Clinical Psychopharmacology 2000;20(1):7-11.

\section{Saarto 2007}

Saarto T, Wiffen PJ. Antidepressants for neuropathic pain. Cochrane Database of Systematic Reviews 2007, Issue 4. [DOI: 10.1002/14651858.CD005454.pub2]

\section{Straube 2008}

Straube S, Derry S, McQuay HJ, Moore RA. Enriched enrollment: definition and effects of enrichment and dose in trials of pregabalin and gabapentin in neuropathic pain. A systematic review. British Journal Clinical Pharmacology 2008;66(2):266-75. [DOI: $10.1111 / \mathrm{j} .1365-2125.2008 .03200 . x]$

\section{Sultan 2008}

Sultan A, Gaskell H, Derry S, Moore RA. Duloxetine for painful diabetic neuropathy and fibromyalgia pain: systematic review of randomised trials. BMC Neurology 2008;8:29. [DOI: 10.1186/1471-2377-8-29]

\section{Tremont-Lukats 2000}

Tremont-Lukats IW, Megeff C, Backonja M. Anticonvulsants for neuropathic pain syndromes. Drugs 2000;60:1029-52.

\section{Wiffen 2011a}

Wiffen PJ, Derry S, Moore RA, McQuay HJ. Carbamazepine for acute and chronic pain in adults. Cochrane Database of Systematic Reviews 2011, Issue 1. [DOI: 10.1002/14651858.CD005451.pub2]

\section{Wiffen 2011b}

Wiffen PJ, Derry S, Moore RA. Lamotrigine for acute and chronic pain. Cochrane Database of Systematic Reviews 2011, Issue 2. [DOI: 10.1002/14651858.CD006044.pub3]

\section{Wolfe 1990}

Wolfe F, Smythe HA, Yunus MB, Bennett RM, Bombardier C, Goldenberg DL, et al. The American College of Rheumatology 1990 Criteria for the Classification of Fibromyalgia. Report of the Multicenter Criteria Committee. Arthritis and Rheumatism 1990;33:160-72.

\section{Wolfe 2010}

Wolfe F, Clauw DJ, Fitzcharles MA, Goldenberg DL, Katz RS, Mease $P$, et al. The American College of Rheumatology preliminary diagnostic criteria for fibromyalgia and measurement of symptom severity. Arthritis Care and Research 2010;62(5):600-10. [DOI: 10.1002/acr.20140] 


\section{References to other published versions of this review}

Wiffen 2010

Wiffen PJ, Collins S, McQuay HJ, Carroll D, Jadad A, Moore RA. WITHDRAWN. Anticonvulsant drugs for acute and chronic pain.

\section{CHARACTERISTICS OF STUDIES}

Characteristics of excluded studies [ordered by study ID]

\begin{tabular}{ll}
\hline Study & Reason for exclusion \\
\hline Gremeau-Richard 2004 & Treatment period of insufficient duration - 14 days, burning mouth syndrome, topical application \\
\hline Harkins 1991 & Treatment period of insufficient duration - 30 days, temporomandibular dysfunction \\
\hline Herman 2002 & Treatment period of insufficient duration - 3 weeks, jaw pain upon awakening \\
\hline
\end{tabular}

\section{AP PENDICES}

\section{Appendix 1. MEDLINE search strategy}

1. exp PAIN/

2. $\exp$ PERIPHERAL NERVOUS SYSTEM DISEASES/

3. exp SOMATOSENSORY DISORDERS/

4. FIBROMYALGIA/ or exp MYOFASCIAL PAIN SYNDROMES/ or POLYMYALGIA RHEUMATICA/

5. ((pain ${ }^{\star}$ or discomfort ${ }^{\star}$ ) adj10 (central or complex or rheumat* or muscl* or muscul* or myofasci ${ }^{\star}$ or nerv* or neuralg* or neuropath $\left.\left.{ }^{\star}\right)\right) . \mathrm{mp}$.

6. (fibromyalgi* or fibrosti* or FM or FMS).mp.

7. ((neur ${ }^{\star}$ or nerv $\left.^{\star}\right)$ adj6 (compress ${ }^{\star}$ or damag $\left.\left.^{\star}\right)\right) \cdot m p$.

8. 1 or 2 or 3 or 4 or 5 or 6 or 7

9. Clonazepam.mp.

10.(Rivotril or Klonopin).mp.

11.9 or 10

12.8 and 11

13.randomized controlled trial.pt.

14.controlled clinical trial.pt.

15.randomized.ab.

16.placebo.ab.

17.drug therapy.fs.

18.randomly.ab.

19.trial.ab.

20.groups.ab.

21.or/13-20

22.exp animals/ not humans.sh.

23.21 not 22

24.23 and 12

\section{Appendix 2. EMBASE search strategy}

1. exp chronic pain/

2. exp peripheral neuropathy/ 
3. exp somatosensory disorder/

4. fibromyalgia/ or exp myofascial pain/ or rheumatic polymyalgia/

5. ((pain ${ }^{\star}$ or discomfort ${ }^{\star}$ ) adj10 (central or complex or rheumat ${ }^{\star}$ or muscl* or muscul ${ }^{\star}$ or myofasci ${ }^{\star}$ or nerv ${ }^{\star}$ or neuralg* or neuropath*)).mp.

6. (fibromyalgi* or fibrosti* or FM or FMS).mp.

7. ((neur ${ }^{\star}$ or nerv $\left.{ }^{\star}\right)$ adj6 (compress ${ }^{\star}$ or damag $\left.\left.{ }^{\star}\right)\right) \cdot m p$.

8. 1 or 2 or 3 or 4 or 5 or 6 or 7

9. clonazepam.mp.

10.(Rivotril or Klonopin).mp.

11.9 or 10

12.8 and 11

13. random*.ti,ab.

14. factorial ${ }^{*}$.ti,ab.

15. (crossover ${ }^{\star}$ or cross over ${ }^{\star}$ or cross-over $^{\star}$ ).ti,ab.

16. placebo* ${ }^{\star}$ ti,ab.

17. (doubl* adj blind*).ti,ab.

18. assign*.ti,ab.

19. allocat ${ }^{\star} . \mathrm{ti}, \mathrm{ab}$.

20.RANDOMIZED CONTROLLED TRIAL.sh.

21.DOUBLE-BLIND PROCEDURE.sh.

22.CROSSOVER PROCEDURE.sh.

23.13 or 14 or 15 or 16 or 17 or 18 or 19 or 20 or 21 or 22

24.12 and 23

\section{Appendix 3. CENTRAL search strategy}

1. MeSH descriptor Pain explode all trees

2. MeSH descriptor Peripheral Nervous System Diseases explode all trees

3. MeSH descriptor Somatosensory Disorders explode all trees

4. MeSH descriptor Fibromyalgia this term only

5. MeSH descriptor Myofascial Pain Syndromes explode all trees

6. MeSH descriptor Polymyalgia Rheumatica explode all trees

7. ((pain ${ }^{\star}$ or discomfort ${ }^{\star}$ ) and (central or complex or rheumat ${ }^{\star}$ or muscl* or muscul ${ }^{\star}$ or myofasci ${ }^{\star}$ or nerv ${ }^{\star}$ or neuralg* or neuropath*)):ti,ab,kw

8. (fibromyalgi* or fibrosti* or FM or FMS):ti,ab,kw

9. ((neur* or nerv $\left.{ }^{\star}\right)$ and (compress ${ }^{\star}$ or damag*)):ti,ab,kw

10. $(1$ or 2 or 3 or 4 or 5 or 6 or 7 or 8 or 9 )

11.clonazepam:ti,ab,kw

12.(Rivotril or Klonopin):ti,ab,kw

13.11 or 12

14.10 and 13

15.Limit 14 to CENTRAL

WHAT' S NEW

\begin{tabular}{lll}
\hline Date & Event & Description \\
\hline 29 May 2019 & Amended & Contact details updated. \\
\hline 11 October 2017 & Review declared as stable & No new studies likely to change the conclusions are expected. \\
\hline
\end{tabular}




\section{HISTORY}

Protocol first published: Issue 12, 2011

Review first published: Issue 5, 2012

\begin{tabular}{lll}
\hline Date & Event & Description \\
\hline 18 July 2013 & Review declared as stable & $\begin{array}{l}\text { This review will be assessed for further updating in } 2020 \text { as it is } \\
\text { unlikely that new evidence will be published. }\end{array}$
\end{tabular}

\section{CONTRIBUTIONS OF AUTHORS}

RAM and SD wrote the protocol. RC and SD carried out searches and assessed studies for inclusion. RC and SD planned to extract data and carry out analyses. RAM acted as arbitrator. All authors were involved in writing the review.

\section{DECLARATIONS OF INTEREST}

SD and RAM have received research support from charities, government, and industry sources at various times. RAM has consulted for various pharmaceutical companies, and received lecture fees from pharmaceutical companies related to analgesics and other healthcare interventions. PW is a full-time employee of the UK Cochrane Centre, funded by the UK National Institute of Health Research and has no relevant interests to declare. RC has no interests to declare. No company with any interest in clonazepam had any involvement in the production of this review.

\section{SOURCES OF SUPPORT}

\section{Internal sources}

- Oxford Pain Relief Trust, UK.

\section{External sources}

- No sources of support supplied

\section{NDEX TERMS}

\section{Medical Subject Headings (MeSH)}

Analgesics [*therapeutic use]; Anticonvulsants [*therapeutic use]; Clonazepam [*therapeutic use]; Fibromyalgia [ ${ }^{\star}$ drug therapy]; Neuralgia [ ${ }^{\star}$ drug therapy]; Pain Management [ ${ }^{\star}$ methods]

\section{MeSH check words}

Adult; Humans 